\title{
Influence of MTP on Surface Roughness and Geometric Accuracy of Machined Surface at WEDM
}

\author{
L'. STRAKA ${ }^{1}, \mathrm{G}$. DITTRICH ${ }^{2}$
}

${ }^{1}$ Technical University of Kosice, Faculty of Manufacturing Technologies with a seat in Presov, Department of Automobile and Manufacturing Technologies, luboslav.straka@tuke.sk

${ }^{2}$ Technical University of Kosice, Faculty of Manufacturing Technologies with a seat in Presov, Department of Automobile and Manufacturing Technologies, gabriel.dittrich@tuke.sk

Abstract. Electrical discharge machining technology is one of the most precise machining methods. Therefore, even the smallest deviation of micro and macro geometry generally has a significant impact on the overall quality of products produced by this progressive technology. The quality of the machined surface after Wire Electrical Discharge Machining (WEDM) is influenced by a large number of factors, most of which are influenced by the Main Technological Parameters (MTP). The aim of the paper was to describe the results of experimental research aimed at assessing the impact of MTP for WEDM on the quality of machined surface in terms of geometric accuracy and roughness parameters $R a$ and $R z$. The samples were made of high alloyed ledeburitic chromium-molybdenumvanadium steel designated EN X155CrVMo12-1 on a Sodick AQ535 electroerosion machine. The tool used was a standard compact brass wire $\phi 0.25 \mathrm{~mm}$ with the designation Elecut Brass CuZn37.

\section{Introduction}

At present, the trend is focused on continuous improvement of product quality. However, the concept of quality includes a number of parameters whose actual values are specified by the customer [1]. One of the basic parameters that the customer limits at WEDM is the roughness of the machined surface. Another not less important parameter is the geometric accuracy of the machined surface. In addition to these basic quality indicators, customers often require the application of materials with specific mechanical, physical and chemical properties [2]. Quite often, high-alloy steels, tungsten carbides and the like are machined using electrical discharge machining technology. As with other progressive technologies and also in WEDM is limited by the extent of use of machined materials [3]. The given limit for WEDM is the required minimum electrical conductivity of the workpiece. In general, any electrically conductive material can be machined with WEDM technology, with almost no limits to the mechanical properties of the material being machined [4]. On the other hand, the advantage of applying this technology is that it can machine complicated shapes that virtually cannot be achieved with other technology [5,6]. At the same time, the machining of complicated product contours often requires in practice a locally limited breaking of the edges or removal of material in a certain sequence or in well-defined layers. These specific requirements in a conventional machining technology generally require the application of multiple tools and equipment, resulting in a prolongation of working. In general, however, the final quality of the machined surface specified by the customer is 
primarily dependent on the MTP setting for WEDM [7,8]. In doing so, the individual combinations of MTP settings determine the resulting intensity of electrical discharges between the workpiece and the tool electrode. The magnitude of the intensity of electric discharges has a significant impact not only on the roughness of the machined surface, but also on its geometric accuracy $[9,10]$. Therefore, the experimental research was aimed at assessing the impact of the discharge energy intensity on the quality of the WEDM surface when machining tool steel labelled EN X155CrVMo12-1 in terms of the parameters of geometric accuracy and roughness of the machined surface.

\section{Material and methods of work}

The SODICK AQ535 electroerosion equipment was used in the production of samples (Fig.1). It is a multi-axis CNC equipment that is used in practice for the production of moulds, shearing tools, electrodes and the like from very hard materials or products with complicated shapes. The basic part of the electroerosion equipment consists of a pulse generator that generates electrical discharges between the workpiece and the tool electrode of varying intensity based on the setting of the respective MTP combination. In the experiment, the connection of the cathode to the wire tool electrode and the anodes to the workpiece were applied.

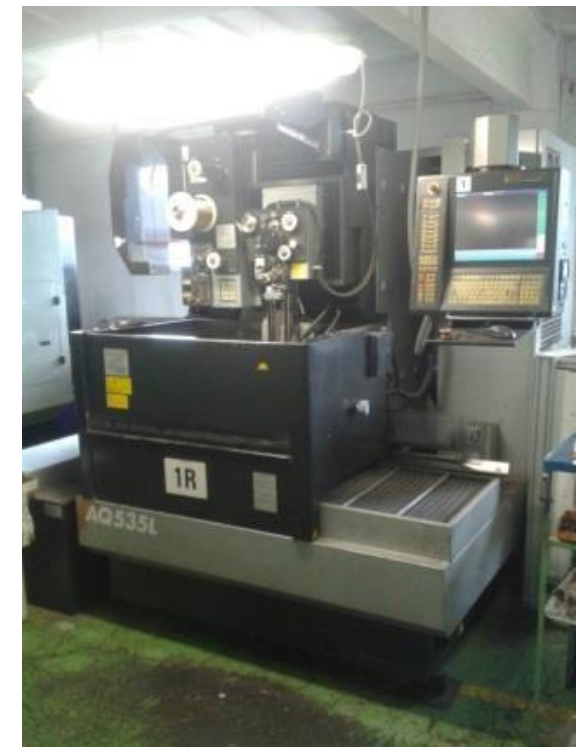

Figure 1. SODICK AQ535 Electroerosion equipment

The samples were immersed in a dielectric liquid based on deionized water during electrical discharge machining. The eroded particles from the machined material as well as the wire tool electrode were flushed with a stream of dielectric fluid through a nozzle with adjustable flushing pressure. Laboratory measuring devices were used to measure the qualitative parameters of the experimental samples produced in terms of roughness and geometric accuracy. The Mitutoyo Surftest SJ 400 contact profilometer (Fig. 2a) was used to measure the roughness of the eroded surface, which is commonly used in practice to measure the roughness, waviness, and primary profile. It is a measuring device with automatic radius and inclination compensation. The contact CNC ThomePräzision machine with Metrolog XG software was used to measure the deviations of the geometric accuracy of the eroded surface (Fig. 2b). 


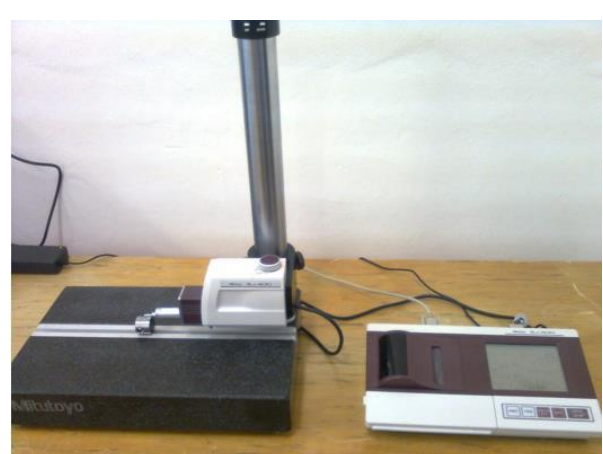

a) measurement of machined surface roughness

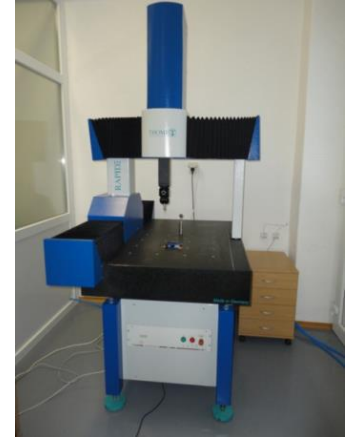

b) measurement of geometric precision deviation of machined surface

Figure 2. Identification of qualitative indicators of machined area of experimental samples.

Within the experiment, a brass cutting wire fi $0.25 \mathrm{~mm}$ manufactured by ELERO, s. $\mathrm{r}$.o. labeled ELECUT BRASS CuZn37, was used to make samples using WEDM technology. It is a standard type of compact wire electrode, which has a relatively high tensile strength $\mathrm{Rm}=980 \mathrm{~N} / \mathrm{mm}^{2}$ with a $63 \% \mathrm{Cu}$ content and $37 \%$ Zinc content. This type of wire electrode can provide the required quality of the machined surface with high productivity and at the same time favorable economic efficiency of the electroerosion process. The samples were made of Böhler tool steel with the designation EN $\mathrm{X} 155 \mathrm{CrVMo12}$-1. It is highly alloyed ledeburitic chromium - molybdenum - vanadium steel, which is characterized by high abrasion resistance, wear resistance and good toughness. At the same time, it has excellent hardenability and dimensional stability. In practice, it is normally used for the production of cold working tools such as shearing and stamping tools, punches, industrial woodworking knives, etc. It is also suitable for the production of simple symmetrical tools for extrusion and pressing, thread rolling tools, but also for the production of very stressed frequent moulds. When using conventional machining methods, it has a worse machinability due to higher $\mathrm{Cr}$ $(11.8 \%)$ and C (1.55\%) contents. The hardness in the annealed state is at the level of max. 255HB, which corresponds to a strength of about $860 \mathrm{MPa}$. The maximum achievable hardness after martensitic hardening is about 61 to 63 HRC. The basic chemical composition of the used tool steel marked EN X155CrVMo12-1 is given in Tab. 1.

\begin{tabular}{ccccccccc} 
Steel marking & \multicolumn{8}{c}{ Percentage of elements (\%) } \\
EN ISO X155CrVMo12-1 & 1.55 & 0.25 & 0.35 & 11.80 & 0.80 & 0.95 & $\max 0.030$ & max 0.030 \\
\hline
\end{tabular}

Table 1. Basic chemical composition of tool steel with the designation EN X155CrVMo12-1.

Prior to electrical discharge machining, it was necessary to heat-treat the material of the experimental samples to achieve the desired properties and to remove internal stresses [12]. Heat treatment of the material of the experimental samples consisted of martensitic hardening and subsequent tempering to remove internal stresses. The martensitic hardening was carried out in the form of a two-stage heating, in which an austenitization temperature of about $1040^{\circ} \mathrm{C}$ was applied. Subsequently, the material was quenched into oil. Immediately after cooling the material, tempering was performed to remove internal stresses at a temperature of about $520^{\circ} \mathrm{C}$, at which a secondary hardness of the base 
material of 56HRC was achieved. If a lower tempering temperature is applied, a higher secondary hardness of the base material would be achieved, but at WEDM there would be a risk of releasing residual internal stresses in the sample base material. This would distort the machined surface and consequently distort the recorded results [13]. In the following Fig. 3 are shown made experimental samples.

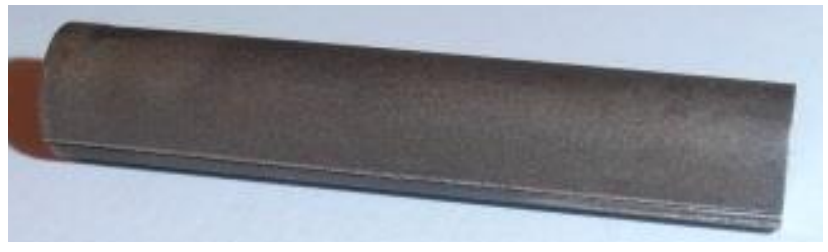

a) cylinder $\phi 8.0 \mathrm{~mm} \times 40.0 \mathrm{~mm}$

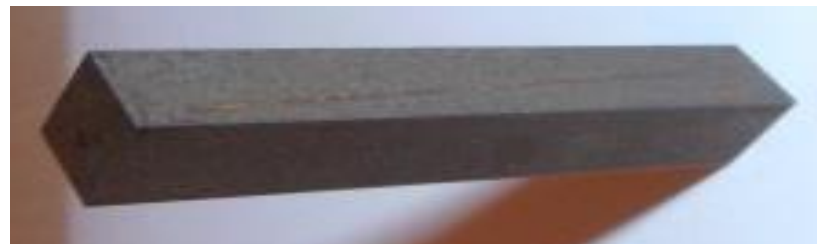

b) prism $8.0 \mathrm{~mm} \times 8.0 \mathrm{~mm} \times 40.0 \mathrm{~mm}$

Figure 3. Experimental samples of tool steel EN X155CrVMo12-1 made using WEDM technology.

Due to the specificity of electroerosion technology two types of experimental samples were chosen. The first type of experimental sample was cylindrical with a diameter of $\phi 8.0 \mathrm{~mm}$ and a length of $40.0 \mathrm{~mm}$ (Fig. 1a). The second type of experimental sample had the shape of a regular prism with an edge of $8 \mathrm{~mm}$ and a length of $40.0 \mathrm{~mm}$ (Fig. 1b). In both types of experimental samples, combinations of MTP settings were applied that corresponded to high, medium and low discharge energy conditions.

\section{Results of experimental measurements}

Experimental samples of both the first and the second type were subjected to the measurement of qualitative parameters of the machined surface related to the roughness of the eroded surface and its geometric deviations. In case of identification of the qualitative indicator, the roughness of the eroded surface, the parameters $R a$ and $R z$ were considered. When identifying a qualitative indicator relating to the geometric accuracy of the eroded surface, the maximum cylindrical variation was considered for the cylindrical sample and the maximum flatness deviation for the prism-shaped sample. Based on the results of experimental measurements, graphical dependencies were subsequently constructed describing the impact of the discharge energy intensity on the machined surface quality in terms of roughness parameters $R a, R z$ (Fig. 4) and geometric deviations of the machined surface (Fig. 5) for WEDM, tool steel EN X155CrVMo12-1 with wire electrode $\phi 0.25 \mathrm{~mm}$ with the designation Elecut Brass CuZn37. 


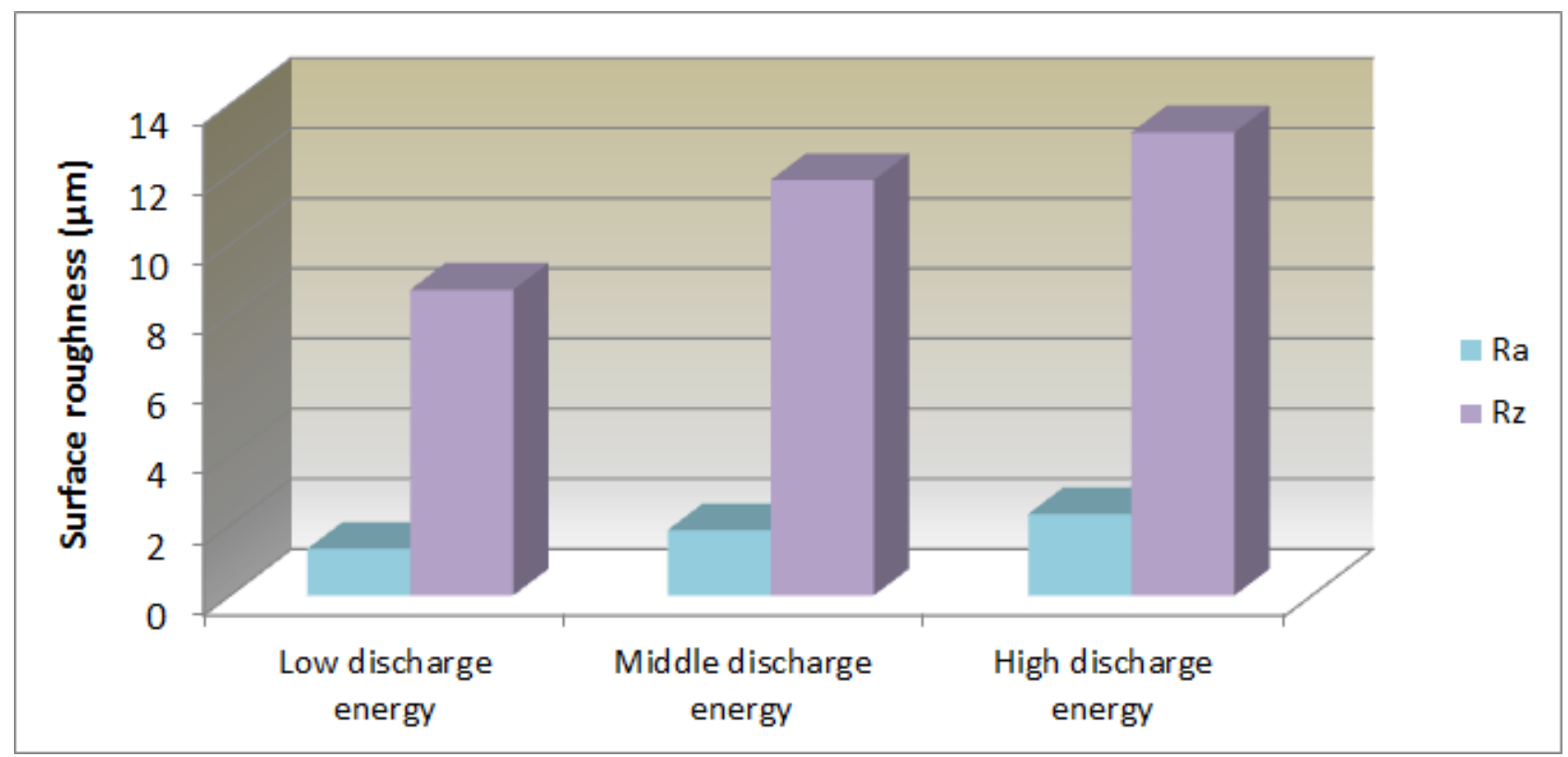

Figure 4. Effect of discharge energy intensity for WEDM, tool steel EN X155CrVMo12-1 with CuZn37 wire electrode on roughness parameters $R a$ and $R z$.

From the graphical dependencies previously described it can be stated that with increasing intensity of discharge energy for WEDM tool steel EN X155CrVMo12-1 with CuZn37 wire electrode, there is a slight increase in the value of the Ra parameter and a significant increase in the surface roughness value of the $R z$ parameter. This increase in the case of the parameter $R a$ represents an increase of about $1.0 \mu \mathrm{m}$ and in the case of the parameter $R z$ an increase of about $4.5 \mu \mathrm{m}$.

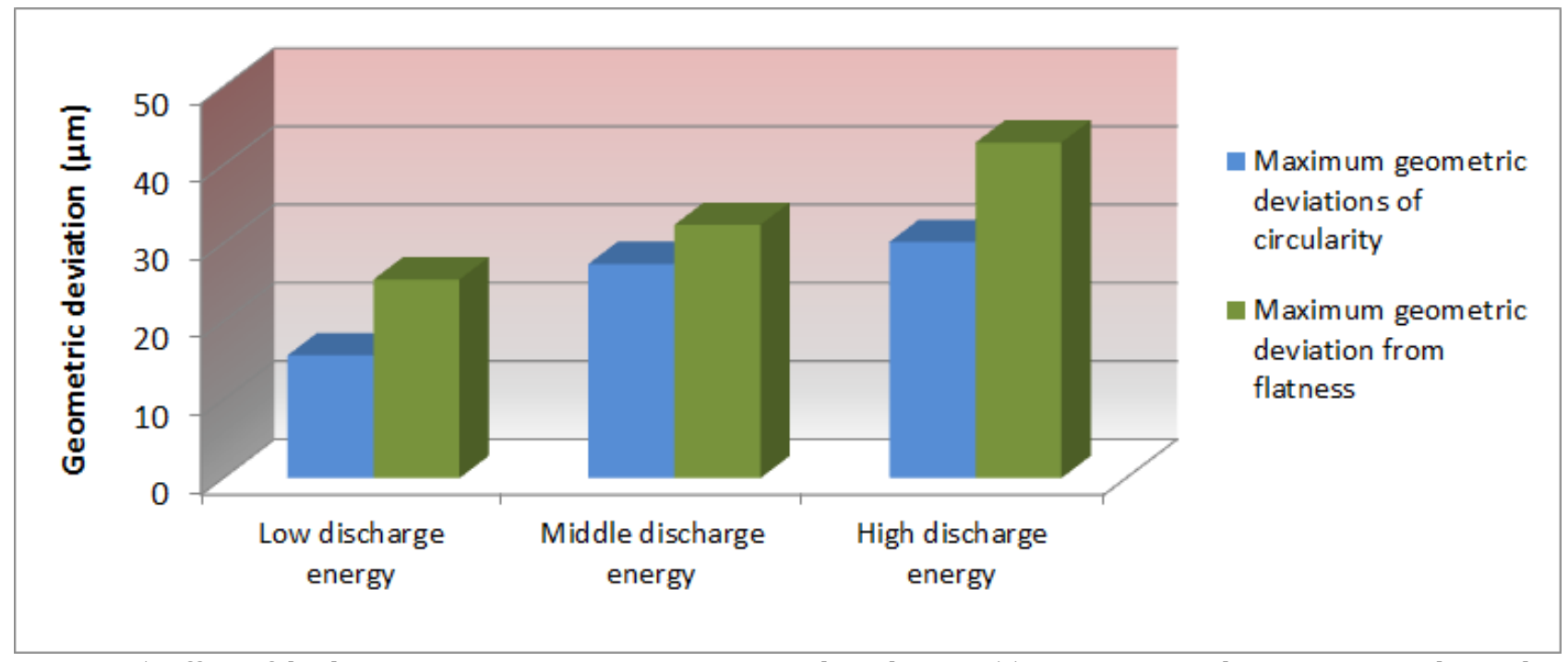

Figure 5. Effect of discharge energy intensity on WEDM tool steel EN X155CrVMo12-1 with CuZn37 wire electrode on the maximum deviation of roundness and flatness.

From the above graphical dependencies it can be seen that with increasing discharge energy intensity for WEDM, tool steel EN X155CrVMo12-1 with CuZn37 wire electrode, the value of maximum deviation increases in both cases. The maximum flatness deviation of the eroded area of the prismshaped experimental sample increased more sharply. The maximum circular deviation of the eroded 
area of the cylindrical experimental sample showed a slight increase. This increase with the maximum deviation of the flatness of the eroded surface was about $17.5 \mu \mathrm{m}$ and with the maximum deviation of the roundness of the eroded surface it was about $14.5 \mu \mathrm{m}$.

\section{Conclusion}

The aim of the paper was to identify the influence of MTP at WEDM, tool steel EN X155CrVMo12-1 with CuZn37 wire electrode on the quality of machined surface in terms of macro and microgeometry. Microgeometry was assessed on the basis of roughness and macrogeometry parameters based on the magnitude of the geometric deviations of the machined surface. The roughness of the eroded surface was evaluated for the roughness parameters $R a$ and $R z$, which provide sufficient information on the microgeometry of the machined surface. The quality of the machined surface in terms of the magnitude of the geometrical deviations of the machined surface was assessed on the basis of the maximum flatness and circularity deviations. The maximum deviation of roundness was measured on experimental samples in the shape of a cylinder and the maximum deviation of flatness was measured on experimental samples in the shape of a regular prism. Based on the results of experimental measurements, it was found that with decreasing discharge energy intensity for WEDM, tool steel EN X155CrVMo12-1 with CuZn37 wire electrode, which is represented by a combination of MTP settings, both qualitative indicators of machined surface significantly improve. However, it should be pointed out that too low a value of the intensity of electric discharges during WEDM leads to a substantial loss of the electroerosion process, making this process economically inefficient [11,14]. Therefore, it is necessary to find a compromise between the quality of the machined surface and the productivity of the electroerosion process.

\section{Acknowledgments}

This work was supported by the project VEGA 1/0205/19.

\section{References}

[1] P. Baron, J. Zajac, M. Pollák, The correlation of parameters measured on rotary machine after reparation of disrepair state, MM Science Journal, 2016, 11(2016), 1244-1248, ISSN 1803-1269.

[2] J. Dubják, J. Pitel', M. Tóthová, Diagnostics of aluminum alloys melting temperature in high pressure casting, Key Engineering Materials, 669 (2016), 110-117, ISSN 1013-9826.

[3] S. Hašová, L'. Straka, Design and verification of software for simulation of selected quality indicators of machined surface after WEDM, Academic Journal of Manufacturing Engineering, 2016, 14(2), 13-20, ISSN 1583-7904.

[4] Mičietová, M. Neslušan, M. Čilliková, Influence of surface geometry and structure after nonconventional methods of parting on the following milling operations, Manufacturing Technology, 2013, 13(2), 199-204. 
International Journal of Engineering and Management Sciences (IJEMS) Vol. 5. (2020). No. 2 DOI: 10.21791/IJEMS.2020.2.12.

[5] K. Mouralova, R. Zahradnicek, P. Houska, Evaluation of surface quality of X210Cr12 steel for forming tools machined by WEDM, MM Science Journal, 2016, 5, 1366-1369.

[6] M. Prislupčák, A. Panda, M. Jančík, I. Pandová, P. Orendáč, T. Krenický, Diagnostic and experimental valuation on progressive machining unit, Applied Mechanics and Materials, Trans Tech Publications, Zurich, Switzerland, 2014, 616, 191-199, ISSN 1660-9336.

[7] L'. Straka, S. Hašová, Prediction of the heat-affected zone of tool steel EN X37CrMoV5-1 after diesinking electrical discharge machining, Proc Inst. Mech. B: J. Eng. Manuf, 2016, 9, 1-12.

[8] L'. Straka, Analysis of Wire-Cut Electrical Discharge Machined Surface, LAP Lambert Academic Publishing, Germany, 2014, 98 p., ISBN 978-3-659-64435-1.

[9] L. Straka, I. Čorný, J. Pitel', Properties evaluation of thin microhardened surface layer of tool steel after wire EDM, Metals, 2016, 6(5), 1-16, ISSN 2075-4701.

[10] L. Straka, I. Čorný, J. Pitel', S. Hašová, Statistical Approach to Optimize the Process Parameters of HAZ of Tool Steel EN X32CrMoV12-28 after Die-Sinking EDM with SF-Cu Electrode, Metals, 2017, $7(2), 1-22$.

[11] A.T. Salcedo, I.P. Arbizu, C.J. Luis Pérez, Analytical modelling of energy density and optimization of the EDM machining parameters of inconel 600, Metals, 2017, 7, (5), 1-21.

[12] R. Świercz, D. Oniszczuk-Świercz, Experimental Investigation of Surface Layer Properties of High Thermal Conductivity Tool Steel after Electrical Discharge Machining, Metals, 2017, 7(12), 550.

[13] M. Ťavodová, Research state heat affected zone of the material after wire EDM, Acta Fac. Tech. $2014,19,145-152$.

[14]W. Zhang, X. Wang, Simulation of the inventory cost for rotable spare with fleet size impact, Academic Journal of Manufacturing Engineering: Editura Politechnica, 2017, 15(4), 124-132, ISSN 1583-7904. 